(1) Semantics \& Pragmatics Volume 2, Article 2: 1-33, 2009

O doi: $10.3765 /$ sp.2.2

\title{
Universal implicatures and free choice effects: experimental data*
}

\author{
Emmanuel Chemla \\ Institut Jean-Nicod, DEC-ENS, Paris \\ University College London
}

Received 2008-11-11 / First Decision 2008-12-08 / Revised 2009-01-10 / Second Decision 2009-02-18 / Revised 2009-02-19 / Third Decision 2009-02-26 / Revised 2009-03-08 / Accepted 2009-03-09 / Published 2009-05-23

\begin{abstract}
Universal inferences like (i) have been taken as evidence for a local/syntactic treatment of scalar implicatures (i.e. theories where the enrichment of 'some' into 'some but not all' can happen sub-sententially):

(i) Everybody read some of the books

$\rightsquigarrow$ Everybody read [some but not all the books].

In this paper, I provide experimental evidence which casts doubt on this argument. The counter-argument relies on a new set of data involving free choice inferences (a sub-species of scalar implicatures) and negative counterparts of (i), namely sentences with the quantifier 'no' instead of 'every'. The results show that the globalist account of scalar implicatures is incomplete (mainly because of free choice inferences) but that the distribution of universal inferences made available by the localist move remains incomplete as well (mainly because of the negative cases).
\end{abstract}

Keywords: experiment, scalar implicatures, free choice

* Many thanks to Gennaro Chierchia, Danny Fox, Bart Geurts, Nathan Klinedinst, Philippe Schlenker and Benjamin Spector as well as to the anonymous reviewers and to the diligent editors of Semantics and Pragmatics. This work was supported by a 'Euryi' grant from the European Science Foundation ("Presupposition: A Formal Pragmatic Approach").

(C)2009 Emmanuel Chemla

This is an open-access article distributed under the terms of a Creative Commons NonCommercial License (creativecommons.org/licenses/by-nc/3.o). 
Emmanuel Chemla

\section{Introduction}

The initial Gricean intuition about scalar implicatures has been both refined and attacked on many occasions. One modest goal of this paper is to investigate in detail a particular argument put forward against a crucial feature of the Gricean approach to scalar implicatures: globalism. Meanwhile, I also present a simple but efficient methodology to collect the relevant empirical data.

In the remainder of this introduction, I introduce the particular problem I focus on: universal scalar (and free choice) inferences emerging from quantified sentences. Such inferences were first introduced as an argument in favor of localism. I add new negative cases to the discussion and show that they are crucial to decide how we should treat these inferences. In section 2, I present the experimental methodology and its results. I conclude in section 3 that neither a localist nor a globalist approach to scalar implicatures has offered the right perspective on universal inferences yet. More precisely, the present results show that the bare globalist approach requires new additions but that the localist addition does not fully account for the whole distribution of universal inferences either.

\subsection{The semantics/pragmatics interface}

Before I introduce the opposition between localist and globalist accounts of scalar implicatures, I would like to explain how this issue contributes to the much more ambitious research program which pertains to understanding the overall architecture of the linguistic competence. Most specifically, the underlying fundamental question is: what and where is the interface between semantics and pragmatics? In other words, what in linguistic communication crucially relies on contextual information? What kinds of contextual information should we identify and take into account?

These broader questions have raised the joint interest of researchers from various fields and from various theoretical and methodological inclinations. In particular, philosophical debates on the semantics/pragmatics interface have provided a variety of definitions and perspectives on meaning, context and the interaction between the two, and these sustain the debate (see for instance recent works by Bach 2002; Carston 2002; Recanati 2004; Szabó 2006). In the present paper, I will leave philosophical aspects aside as much as possible and adopt perspectives which are more common to linguists or psychologists. 
Universal implicatures and free choice effects

There are a variety of linguistic phenomena of interest for theorists who want to study the distinction between semantics and pragmatics (e.g., indexicals, metaphors, presuppositions). However, scalar implicatures constitute an excellent point of departure for several reasons I summarize here and which will become more concrete in the following sections. First, the intuitive appeal of the pragmatic approach to scalar implicatures is such that various scholars have been compelled to defend it from a variety of attacks. The ensuing debate has led to a very rich description of the phenomenon. Second, most theories of scalar implicatures are expressed in very explicit formal frameworks. The predictions of the various theories in competition are thus unambiguous and fine-grained, hence they are testable. Finally, the debate can be revealed with a rather specific question about scalar implicatures: are they local or global? I will show below that despite the simplicity of this general property, it distinguishes between pragmatic and non-pragmatic theories.

\subsection{Scalar implicatures}

Even though its bare meaning does not exclude a situation in which John read all the books, an utterance of (1a) most naturally conveys the same information that (1b) and (1c) assert:

(1) a. John read some of the books.

b. John read only some of the books.

c. John read some of the books and he did not read all the books.

Hence, (1a) normally licenses the inference that 'John did not read all the books'. This inference is called a scalar implicature. If we compare (1a) and (1b), it seems that scalar implicatures arise via the (optional) application of some linguistically invisible operation $\mathbf{O}$ which operates in (1a) in the same way as the word 'only' operates in (1b): it enriches the meaning of its input with the negation of the meaning of some of its alternatives. This is schematized below. A more complete formal description of $\mathbf{O}$ and its denotation is given in appendix A. ${ }^{1}$

1 Here are several notational shortcuts I will use throughout:

- As far as the formal computations are concerned, $\mathbf{O}$ is treated as the same kind of object as explicit 'only': the denotation of $\mathbf{O}$ is a function from propositions to propositions.

- ' $X \equiv Y$ ' should be read as 'the denotations of $X$ and $Y$ are equivalent'. Notice that these denotations may take into account pragmatic information if the $\mathbf{O}$ operator is to be 
Emmanuel Chemla

(2) a. $\mathbf{O}$ (John read some of the books)

$\equiv$ John read some $\wedge \neg($ John read all)

b. only(John read some of the books)

$\equiv$ John read some $\wedge \neg($ John read all $)$

There is no controversy that an operation like $\mathbf{O}$ can provide a good characterization of the scalar implicatures of a sentence. The question under debate is: what is the nature of this operation?

\subsection{The globalist view (neo-Gricean)}

The neo-Gricean view is that $\mathbf{O}$ embodies pragmatic reasoning. In this tradition, $\mathbf{O}$ is called an exhaustivity operator (following work by Groenendijk \& Stokhof 1997 on questions, see van Rooij \& Schulz 2004 and Spector 2006 for applications to scalar implicatures). Crucially, the input to $\mathbf{O}$ is a whole utterance and its output depends solely on the meaning of its input and of the alternatives of its input. These constraints are dictated by the intuition that scalar implicatures arise from pragmatic reasoning based on the following two components. First, sentences have alternatives. For instance, the sentences in (3) are alternatives to each other: ${ }^{2,3}$

understood as a pragmatic device.

- When there is no risk of confusion, I may write ' $X(Y)$ ' to refer to the result of merging $X$ and $Y$ (and where semantic composition requires that $X$ applies to $Y$ ). Thus, parentheses merely represent the scope of $X$. This shortcut is used in (2) (consider in particular (2b) where the left-hand side stands for the phrase obtained by merging 'only' and 'John read some of the books').

- Symbols like $\wedge$ and $\neg$ are used as propositional operators with their intuitive meanings. I use them to highlight the contributions of $\mathbf{O}$ and explicit 'only'.

2 These alternatives are said to arise from a scale of competition between the items 'some (of)' and 'all' (see Horn 1972, Gazdar 1979 and Matsumoto 1995 for arguments in favor of the necessity of scales). This explains the name of these inferences: scalar implicatures. Various people believe that lexical scales are mere stipulations and propose other tools to derive the appropriate alternatives (see in particular Katzir 2007).

3 Importantly, it is possible that the relevant notion of alternatives applies to phrases rather than to whole sentences. In fact, every approach postulates a local origin to alternatives: the comparison of two (lexical) items in the same scale or of two structures with comparable complexity. The divergence between globalism and localism lies elsewhere, namely in the role given to these alternatives. 
Universal implicatures and free choice effects

(3) Alternatives:

a. John read some of the books.

b. John read all the books.

Second, the use of sentences with alternatives is governed by general principles of conversation like the maxim in (4):

(4) Quantity+Quality (adapted from Grice 1967; see also Ducrot 1969): Among a set of alternatives, use the logically strongest true alternative.

From these premises, we can explain how the scalar implicature of (1a) arises. First, note that (3b) is stronger than its alternative (1a)/(3a). Hence, assuming that the speaker obeyed the maxim in (4), it follows that s/he does not (particularly) believe that ( $3 b$ ) is true. This is most probably because the speaker actually believes that ( $3 \mathrm{~b})$ is false. ${ }^{4}$ This last step ends the derivation of the scalar implicature: John did not read all the books.

In this framework, exhaustivity operators are technical devices which model the pragmatic reasoning above (this explains why $\mathbf{O}$ is "linguistically invisible" to begin with). On this view, it is crucial that $\mathbf{O}$ applies to whole utterances because it is the natural level of application for a maxim like (4).

\subsection{The localist view}

Various authors have disputed the pragmatic view I described above by presenting various benefits we could gain if we abandon globalism and accept that $\mathbf{O}$ may apply much more freely (at least since Cohen 1971; see also Levinson 2000, Recanati 2003, Landman 1998, Chierchia 2004 and Fox 2007 for influential accounts with various theoretical inclinations). On this view, $\mathbf{O}$ cannot be thought as a shortcut for pragmatic reasoning as described above; rather, it belongs to the class of standard grammatical operators. As such, $\mathbf{O}$ may appear at embedded scope sites and contribute to the recursive computation of the meaning of a sentence.

The benefit of this flexibility is that it produces more possibilities for a given sentence and has the potential to explain more inferences. For example, a sentence like (5) would become 2-way ambiguous because $\mathbf{O}$ could be applied at two different scope sites: 5

4 This last step, sometimes called the epistemic step, requires more discussion. See for instance Spector (2003), van Rooij \& Schulz (2004) and Sauerland (2004).

5 There are more options if we take into account multiple insertions of $\mathbf{O}$ or its absence altogether. 
Emmanuel Chemla

(5) Every student read some of the books.

a. $\mathbf{O}$ (Every student read some of the books)

$\equiv$ Every student read some $\wedge \neg$ (every student read all)

b. Every student is an $x$ such that $\mathbf{O}(x$ read some of the books $)$

$\equiv$ Every student is an $x$ such that ( $x$ read some $\wedge \neg(x$ read all))

$\equiv$ Every student read some but not all the books.

The analysis in (5a) corresponds to the globalist approach to scalar implicatures: $\mathbf{O}$ applies on top of the sentence and negates relevant alternatives (one may simply proceed by analogy with (2) or follow the proposed semantics for interpretation of $\mathbf{O}$ given in appendix A after Fox 2007). We obtain that (5) should be interpreted as meaning: every student read some of the books and at least one of the students did not read all the books.

However, one may argue that this prediction is too weak and that the right theory should predict a universal implicature:

(6) Every student read some of the books

$\rightsquigarrow$ No student read all the books.

This prediction is actually the one obtained with a local application of $\mathbf{O}$ as in (5b). The existence of this universal inference has been put forward as an argument in favor of localism. In this paper, I will cast doubt on this argument and set up a new empirical puzzle.

\subsection{The form of the counter-argument}

Chierchia, Fox \& Spector (2008) recently reviewed a whole range of arguments in favor of localist accounts of scalar implicatures (see also Sharvit \& Gajewski 2008). In a nutshell, localist applications of $\mathbf{O}$ operators make it a very powerful device which predicts many potential implicatures, and these authors present sophisticated tools to show that a wide range of the localist predictions are attested.

Unsurprisingly, opponents have tried to show that the localist device is too powerful. This is the case, in particular, for Geurts \& Pouscoulous (2008), who present experimental data which demonstrate that the localist predictions are subjectively much less robust than their mere globalist counterparts. However, there are simple ways to account for such differences within the localist approach. For instance, one could argue that the local insertion of $\mathbf{O}$ as in (5b) is somewhat costly and that this cost could explain why the localist inference is not robust. In this paper, I develop a different type of 
Universal implicatures and free choice effects

argument against localist models. Despite the flexibility of the localist $\mathbf{O}$ operator, I will show that it is not powerful enough. In particular, I do not ask directly whether universal inferences like (6) exist. Rather, I ask whether their distribution is as predicted by localist theories. To that end, I will investigate empirical data obtained from two modifications of (5). First, I will consider quantified sentences with the quantifier 'no' rather than 'every'. Second, I will investigate the behavior of free choice inferences (arguably a particular kind of scalar implicature, see e.g., Kratzer \& Shimoyama 2002 and Alonso-Ovalle 2005) in the same type of configuration.

\subsection{Predictions}

In this section, I present the phenomena that I propose to investigate experimentally and the corresponding globalist and localist predictions.

\subsubsection{Positive implicatures}

Let us first consider the usual paradigm as illustrated with the following pair of inferences:

(7) a. John read some of the books. $\rightsquigarrow$ John didn't read all the books.

b. Every student read some of the books.

$\rightsquigarrow$ Each student is such that he didn't read all the books.

I will refer to these configurations as "positive": the (weak) scalar item 'some' is embedded in a positive (upward-entailing) environment. This configuration gives rise to scalar implicatures. On the globalist view, (7a) should be licensed and ( $7 \mathrm{~b})$ should not (i.e. the predicted scalar implicature is weaker); on the localist view, ( $7 \mathrm{~b})$ is also a possible scalar implicature (see (5)).

\subsubsection{Negative implicatures}

If the examples above are positive implicatures, the next set of inferences can be called negative implicatures: a (strong) scalar item 'all' appears in a negative (downward-entailing) environment. It might be worth mentioning that this configuration (also called indirect scalar implicatures) required various technicalities from the very first versions of localist theories like Chierchia's (2004) theory. Yet, to my knowledge, the quantified versions of 
this configuration has not received much attention in the debate between localism and globalism.

Consider the inferences described in (8):

(8) a. John didn't read all the books. $\rightsquigarrow$ John read some of the books.

b. No student read all the books. $\rightsquigarrow$ Each student read some of the books.

On both the localist and the globalist view, the inference in (8a) should be licensed as a standard case of (indirect) scalar implicature: we can derive this inference if we plug the operator $\mathbf{O}$ on top of the sentence. This is spelled out in (9):

(9) $\mathbf{O}($ not(John read all the books))

$\equiv \operatorname{not}($ John read all $) \wedge \neg($ not $($ John read some $))$

$\equiv \operatorname{not}(\mathrm{John}$ read all $) \wedge$ John read some

Interestingly, contrary to the situation for its positive counterpart ( $7 b$ ), localist and globalist accounts agree that ( $8 \mathrm{~b})$ should not be licensed. As before, the globalist application of $\mathbf{O}$ yields a weak existential inference:

(10) $\mathbf{O}$ (No student read all the books)

$\equiv$ No student read all $\wedge \neg$ (no student read some)

$\equiv$ No student read all $\wedge$ some student read some

However, contrary to the situation in the positive case, localist applications of $\mathbf{O}$ do not offer any stronger prediction. The reason for this is that there is no position where $\mathbf{O}$ could be fruitfully inserted. Inserting $\mathbf{O}$ right above 'all' will not produce any result because ' $\mathrm{O}(x$ read all the books)' is not different than ' $x$ read all the books': $\mathbf{O}($ all $) \equiv$ all. The only option left to derive the universal inference (8b) is to decompose 'No $P Q$ ' as 'Every $P \neg Q^{\prime}$ and claim that the position right above the dislocated negation is available to $\mathbf{O}$ insertion as in (11):

(11) Every student is an $x$ s.t. $\mathbf{O}($ not $(\mathrm{x}$ read all the books))

Hence, unless we postulate a split of the quantifier 'no' which would provide the syntactic position needed to insert $\mathbf{O}$, localist theories do not predict the inference (8b). Interestingly, Jacobs (1980), Kratzer (1995), Potts (2000) and Penka \& von Stechow (2001) argued on independent grounds in

6 'Every' represents a quantifier hidden in 'no' with "positive” universal force (like standard 'every'). 
Universal implicatures and free choice effects

favor of some decompositional analysis of 'no'.7 However, even these analyses provide further arguments against (11) because the syntactic decomposition they argued for is not $\forall \neg$ as in (11), but rather its semantically equivalent $\neg \exists .8,9$

In sum, the required syntactic split of the quantifier 'no' is not an option and localist theories attribute a different status to the universal inferences in ( $7 \mathrm{~b})$ and ( $8 \mathrm{~b})$ : the former should be readily available, the latter should not. On the other hand, these same inferences are given the same status by globalist theories (according to which these inferences are not scalar implicatures).

The experimental data below do not show evidence that the localist asymmetry between positive and negative cases is warranted. The comparison with free choice inferences will make the situation more dramatic for both the localist and the globalist camps.

\subsubsection{Positive free choice effects}

Let us consider a different set of data. The inferences illustrated below are called "free choice" inferences (Kamp 1973):

(12) a. John is allowed to have an apple or a banana. $\rightsquigarrow$ John can choose between the two fruits.

b. Every student is allowed to have an apple or a banana. $\rightsquigarrow$ Every student can choose between the two fruits.

Inferences like (12a) have been argued to be standard cases of scalar implicatures (e.g., Kratzer \& Shimoyama 2002 and Alonso-Ovalle 2005) and Fox (2007) explicitly showed that an operator like $\mathbf{O}$ can account for such inferences. ${ }^{10}$ In other words, even though I will not go into the details of

7 Geurts (1996) argued against a decompositional analysis altogether.

8 This decomposition is often reflected in the overt morphology of the quantifier: English 'no-one', German ‘k-ein', French 'auc-un', Spanish ‘ning-uno'... Bech (1955) refers to such morphological considerations as "Kohäsion."

9 Interestingly, these considerations serve as the basis of a criticism against some syntactic accounts of neg-raising (see Horn 1978 and Gajewski 2005, 2007). These run entirely parallel to the difficulties for localist approaches to scalar implicatures to be discussed below.

10 In Fox (2007), this result is proved in a localist framework but notice that the operator is applied globally to obtain (12a). Readers familiar with these results may also have noticed that Fox makes use of two operators $\mathbf{O}$ applied on top of each other, I use only one operator here for the sake of simplicity. In fact, technically speaking, it is possible to modify the definition of the operator to need only one application: $\mathbf{O}$ can be the operation obtained from applying Fox's operator iteratively until it does not yield any additional implicatures. See 
how this prediction comes about, it is both conceptually motivated and made formally possible that the following application of $\mathbf{O}$ predicts the inference (12a):

(13) $\mathbf{O}$ (John is allowed to have $A$ or $B$ ) implies that John is allowed to have $A$ and that John is allowed to have $B$.

Let us now look at the universal counterpart of this inference in (12b). The configuration is similar to (5) where there is a scalar item in the scope of a universal quantifier. This sentence can be analyzed in two ways:

(14) a. $\mathbf{O}$ (Everyone is allowed to have $A$ or $B$ )

b. Everyone is an $x$ such that $\mathbf{O}(x$ is allowed to have $A$ or $B)$

The globalist analysis is in (14a). The globalist analysis is in (14a). The prediction made by this analysis depends on details that I have not presented fully as regards the interpretation of $\mathbf{O}$ (see appendix A for these details). The crucial point for our purposes is that the prediction is not universal (see A.3). On the other hand, the latter analysis in (14b) does straightforwardly predict the universal inference in (12b) and this can be seen by importing the results of (13) into (14b).

\subsubsection{Negative free choice effects}

As in the case of standard implicatures, we can investigate the negative counterparts of the free choice inferences discussed in (12):

(15) Context: Every student is required to do $A$ or $B$, we don't know yet whether some students will have to do both.

a. John is not required to do $A$ and $B$.

$\rightsquigarrow$ John may choose between $A$ and $B$.

b. No student is required to do $A$ and $B$.

$\rightsquigarrow$ Every student may choose between $A$ and $B$.

The situation is the same as in (8) for implicatures. First, (15a) is predicted to be licensed according to both globalist and localist approaches. Second, the predictions from a globalist or a localist application of $\mathbf{O}$ collapse for the negative universal version (15b) because there is no embedded scope site

Spector (2007a) for a discussion of this type of iterative process in a neo-Gricean framework. See Schulz (2003) for discussion of free choice effects with a globalist perspective. 
Universal implicatures and free choice effects

where $\mathbf{O}$ could be inserted and yield any additional effect: the inference in (15b) should not be licensed (see discusion in section 1.6.2).

\subsection{Summary}

In the previous sections, I showed that modifications of the standard 'everysome' configuration could help distinguish further localist and globalist theories. In particular, more distinctions arise if we examine systematically negative counterparts of standard examples (schematically, the configuration 'no-all') or if we take free choice inferences into account. We can now sum up the main predictions in terms of the differences that can be expected between universal inferences in various configurations:

(16) Positive vs. negative cases (for both scalar implicatures and free choice):

a. Globalists: there should be no difference between positive and negative cases.

The universal inferences should be absent in both cases.

b. Localists: there should be a difference between the positive and the negative cases.

The universal inference should arise in the former and not in the latter case.

(17) Positive case, scalar implicatures (SI) vs. free choice (FC):

a. Globalists: there should be no difference between SI and FC. The universal inferences should not arise.

b. Localists: there should be no difference between SI and FC. The universal inferences should arise in both cases.

These predictions are represented graphically in figures 1(a) and 1(b) below. I use the non quantified cases as a visual baseline (I call them individual by contrast with the universal cases, these are schematically of the form 'John-some' instead of 'every-some'). A point high in the graph means that the corresponding inference is (or can be) predicted and a low point means that the corresponding inference cannot be predicted. ${ }^{11}$

11 As a result, this graphical representation does not take into account the fact that in the localist framework for instance, an inference might be predicted but yet disfavored in favor of the globalist version for independent reasons. Note that the predictions in (16) and (17) (or at least the first half of each statement about differences between inferences rather than 


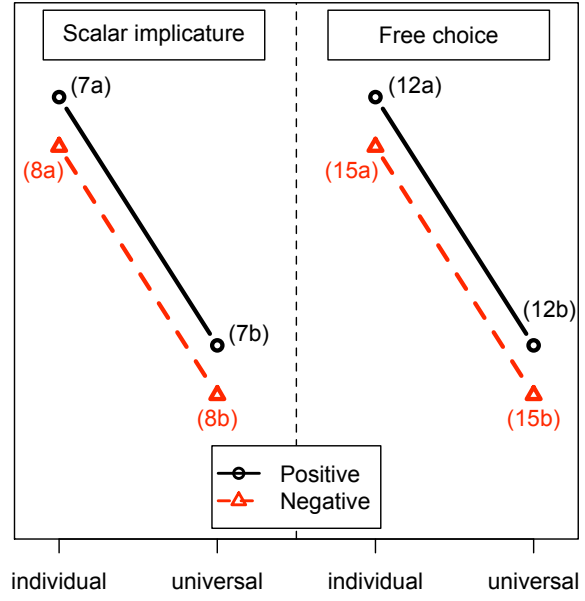

(a) Predictions from a globalist treatment of implicatures

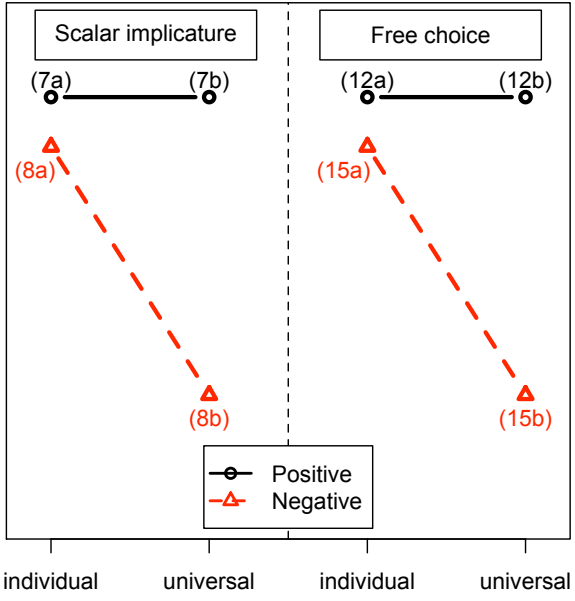

(b) Predictions from a localist treatment of implicatures

Figure 1 Comparing the predictions

\section{Experiment}

The goal of this experiment is to test the predictions discussed above in (16) and (17) and schematized in figures $1(\mathrm{a})$ and $1(\mathrm{~b})$. In short, this experiment collects fine-grained judgments about the relevant inferences from naive participants.

\subsection{Experimental setting}

Participants. The experiment was carried out in French; 16 native speakers aged between 18 and 31 years participated to the experiment. None of them had any prior exposure to formal linguistics.

Instructions. The instructions were given via the set of examples reported in figure 2. The participants were asked to tell whether a sentence "strongly suggested" another one or not. While examples (i) and (ii) are uncontroversial, example (iii) was used to illustrate that the task was not a logical task but rather a matter of personal judgment. Participants were asked to give their

about the presence or absence of inferences) are weaker and do take into account some such possible amendments to the bare localist view. 
Universal implicatures and free choice effects

General context: The teacher is about to give the results of the last exams. He says:

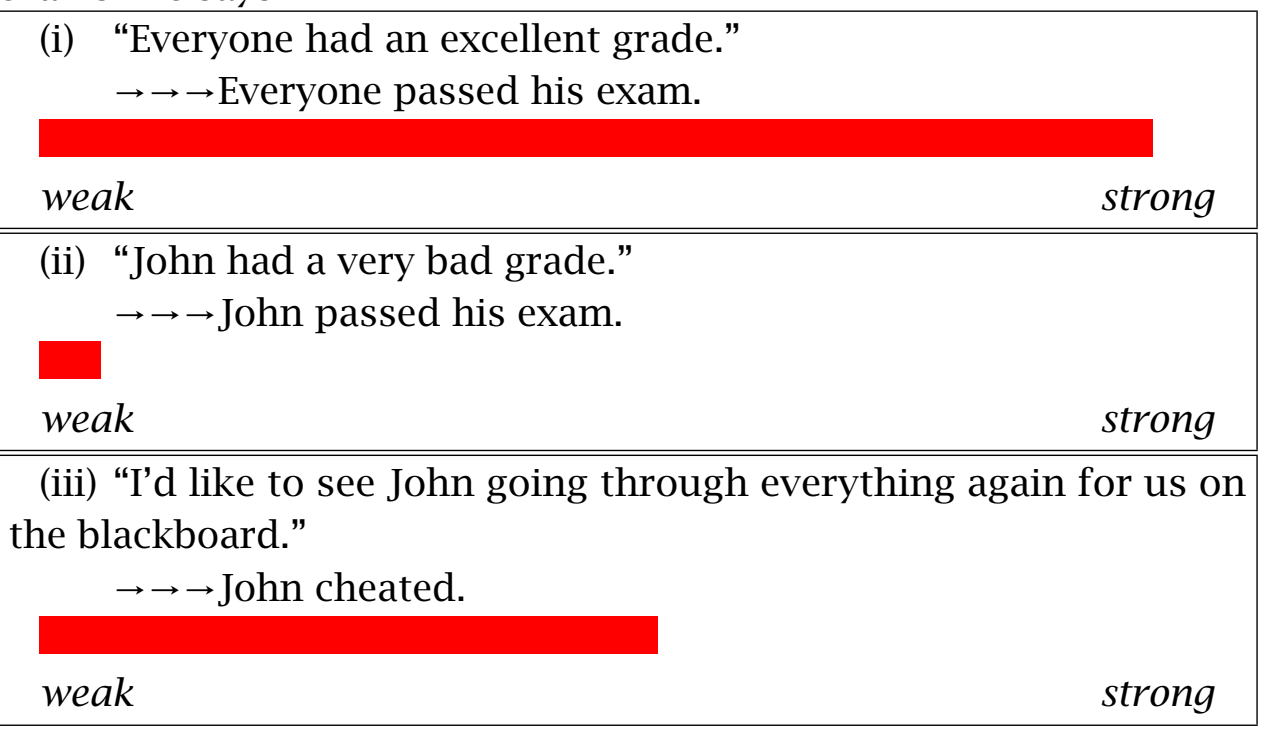

Figure 2 Training example (French version in (32) in appendix C).

judgments by setting the length of a red line for each item: the longer the line, the stronger the inference. The instructions presented to the participants are reported extensively in appendix B. These instructions were written with two main goals in mind: 1) provide a general context for the task (even though each example came with a further reinforcement and refinement of this context) and 2) give a sense of what the inferential task was about (participants unanimously said during the debriefing interview that the task was clear and unambiguous).

Experimental paradigm. This paradigm closely resembles magnitude estimation (see Stevens 1956) which is discussed for instance in Bard, Robertson \& Sorace (1996), Schütze (1996) and Cowart (1997) for its applications in syntax. The two main differences in the present experiment are that 1) in a standard magnitude estimation experiment, participants are explicitly instructed to represent with the line length the intuitive ratio between the stimulus and a reference point (modulus), and 2) the judgments that were prompted were robustness of inferences (rather than, e.g., grammaticality 
Emmanuel Chemla

judgments of individual sentences). ${ }^{12,13}$

The present measure may seem unusual to linguists. For instance, it might sound more natural to ask a binary question (does the inference follow? yes or no). However, based on debriefing interviews, participants did not find it confusing in any way and it is in fact natural to believe that judgments about linguistic inferences can be spontaneously graded, just as in the case of grammaticality judgments. ${ }^{14}$ The goal of this study is to assess whether various inferences are of different types, and, presumably, different graded judgments would reveal different types of inferences.

Another property of this task is that it is entirely explicit: participants were asked to appeal to introspection to report their intuitions. This could raise various worries. Most prominently, one might wonder whether participants developed strategies for answering rather than consulting their intuitions. Note, however, that the present experiment was extremely short ( 4 screens of 4 items) and it is unlikely that they could have developed any strategy in such a brief period which would explain the present results.

Finally, the fact that the alleged inference was explicitly mentioned may have an effect on the derivation of the inference (see for instance, discussion of the difference between an inferential task and a verification task in Geurts \& Pouscoulous 2008). Lacking any evidence to the contrary, we assume that this has a uniform effect on all conditions, and even if it might prevent us from drawing strong conclusions from absolute results, the differences between conditions remains meaningful.

Experimental conditions. There were three experimental factors with two levels each:

(18) Inference type: scalar implicature (SI) vs. free choice inferences (FC).

(19) Environment: positive vs. negative.

(i.e. was the scalar item in a positive or a negative environment?)

(20) Domain: individual vs. universal.

(e.g., in the examples discussed in section 1.6, (a)s illustrate individual inferences and (b)s are their universal counterparts).

12 I use (and discuss in more detail) a similar paradigm in Chemla (2009b). In particular, the present type of continuous judgment was explicitly compared with corresponding binary judgments.

13 As is standard, the dependent measure was the percentage of the line filled for each item.

14 I use the word 'judgment' here to refer to the answers given by the subjects. This judgment is certainly affected by various considerations (perhaps coming from different cognitive systems) and I am not trying to discuss whether the linguistic component of this judgment is binary or graded in nature. 
Universal implicatures and free choice effects

There were two items for each combinatorial condition and the complete list of $2 \times(2 \times 2 \times 2)=16$ inferences was presented to each participant. The full list of items is in appendix C. As already mentioned, there was no reason to expect that the validity of the results could be threatened by response strategies, and hence no filler items were included.

Presentation of the items. The first item presented to the participants repeated the training example so that they could get used to the general display and to the task. Each screen prompted the judgments for four inferences at once, all of them being either scalar implicatures or free choice inferences. The other factors cycled through the $2 \times 2$ remaining combinations; see figure 3 for an example. The order of presentation of inferences in each screen, as well as the order of the items within a screen was randomized across subjects (with the exception that negative and positive inferences were not paired with each other in the same screen because they were headed by two different "general contexts").

\subsection{Results}

The results are represented graphically in figure 4. I describe them below in more detail. The statistics reported here come systematically from 2-tailed paired $t$-tests or repeated measures analysis of variance (ANOVA), and $\eta^{2}$, i.e. partial eta-squared, a standard measure of effect size for multi-factor analyses, showing how much of the observed variation in a measurement can be attributed to a specific factor. Notice also that to study the effect of condition $X$ on universal inferences, I avoid relying on direct comparisons between the corresponding universal inferences alone. Rather, I report interactions between condition $X$ and the domain (universal vs. individual) so that the individual non-controversial cases serve as a baseline.

\subsubsection{Scalar implicatures}

Universal $<$ Individual. For scalar implicatures (left-hand side of the figure), the universal inference is significantly less robust than the individual inference, both in the positive $\left(F(1,15)=26.8, p<.05, \eta^{2}=.39\right)$ and in the negative case $\left(F(1,15)=22.5, p<.05, \eta^{2}=.38\right)$. This first result shows (at the very least) that the present paradigm is powerful enough to detect differences between inferences. 
Emmanuel Chemla

General context: We know that nobody will be allowed to give the teacher both the dissertation and the commentary for correction. The teacher gives further instructions:

"John is allowed to give me the dissertation or the commentary."

$\rightarrow \rightarrow \rightarrow$ John can choose which of the two he will give to the teacher. weak

strong

"Everybody is allowed to give me the dissertation or the commentary." $\rightarrow \rightarrow \rightarrow$ Everybody can choose which of the two he will give to the teacher. weak strong

General context: We know that everyone will be allowed to give the teacher (at least) the dissertation or the commentary for correction (we don't know yet whether some will have to give him both). The teacher gives further instructions:

"John does not have to give me the dissertation and the commentary." $\rightarrow \rightarrow \rightarrow$ John can choose which of the two he will give to the teacher. weak strong

"Nobody has to give me the dissertation and the commentary." $\rightarrow \rightarrow \rightarrow$ Everybody can choose which of the two he will give to the teacher. weak strong

Figure 3 Example of a screen of items (actual French version in (35)). The order of the items was randomized, but for each screen the positive and negative cases were presented in distinct frames headed by their respective contexts and thus they did not intertwine. 


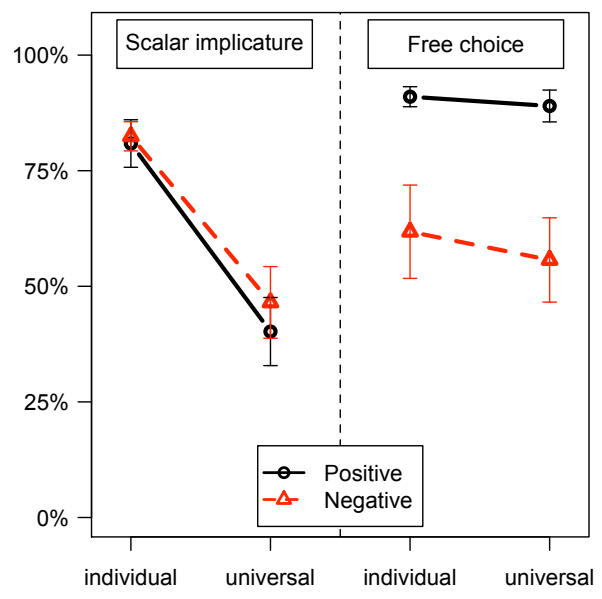

Figure 4 Actual results - mean rates for each inference (\% of the line filled)

Positive $=$ Negative. However, no difference is detected between the positive and the negative configurations. The interaction between environment (positive and negative), and domain (individual vs. universal) is not significant $(F<1$, n.s.). In fact, the positive and the negative cases look exactly the same.

Overall. These results seem to support the globalist approach (see predictions in (16)).

\subsubsection{Free choice inferences}

Universal $=$ Individual. For free choice inferences (right-hand side of the figure), the individual and universal inferences are not significantly different (in the positive environment: $F<1$, n.s., negative environment: $F<1$, n.s.).

Positive $=$ Negative. ${ }^{15}$ Crucially, as before, the interaction between the positive/negative factor, and the type of inference (individual vs. universal) is not significant $(F<1$, n.s.). Note however that there is now a significant main effect of the positive/negative factor $\left(F(1,15)=9.82, p<.05, \eta^{2}=.28\right) .{ }^{16}$

Overall. These results first seem to give an advantage to the globalist approach in the sense that the positive and the negative configurations do

15 Again, this is true if we take the individual case as the baseline.

16 There is no corresponding difference between the positive and the negative cases for scalar implicatures. In fact, the interactions between positive/negative and scalar implicature/free choice are significant both when restricted to the individual cases $(F(1,15)=6.99, p<$ $\left..05, \eta^{2}=.24\right)$ and to the universal cases $\left(F(1,15)=6.12, p<.05, \eta^{2}=.22\right)$. 
not differ (see prediction (16)). However, the universal inferences are now robust (as robust as their individual baseline) and neither the localist nor the globalist account can explain this result.

\subsubsection{SI vs FC}

Universal SI $<$ Universal FC. The $2 \times 2$ interaction between inference type (SI vs. FC) and domain (individual vs. universal, the individual case being used as a baseline) is significant both in the positive case $(F(1,15)=20.5, p<$ $\left..05, \eta^{2}=.36\right)$ and in the negative case $\left(F(1,15)=13.6, p<.05, \eta^{2}=.32\right)$.

Overall. There is a qualitative difference between universal scalar implicatures and free choice inferences. This is a puzzling result to which I return below.

\section{Discussion}

\subsection{Against a localist approach}

The data presented in the previous section show that if they exist, universal inferences of type ( $7 \mathrm{~b})$ are less robust than standard cases of scalar implicatures (in agreement with Geurts \& Pouscoulous 2008). This is already surprising from a localist perspective which would not predict this difference between the universal and the individual cases but rather a non-attested difference between the positive and the negative configurations (see prediction (16)).

Furthermore, imagine that we could explain why the universal inferences were weakly endorsed for scalar implicatures. One would still need to explain why the apparently entirely similar universal inferences for free choice effects are robustly endorsed (see prediction (17b)). After all, both universal inferences should come from the same mechanism: the (local) application of the operator $\mathbf{O}$ in the very same position.

At the very least, the results of the present experiment show no evidence in favor of a localist approach to scalar implicatures, contrary to the reason why the relevant linguistic examples were first discussed in the literature. Much more controversially, one could say the present results suggest that the nuclear scope of 'every' is not available to the local insertion of $0 .{ }^{17}$

17 In their defense of the localist approach, Chierchia et al. (2008) acknowledge that there are restrictions on the insertion of $\mathbf{O}$. On their view, this claim may thus be rephrased by saying that the scope of universal quantifiers is part of the set of positions were $\mathbf{O}$ cannot be inserted. 
Universal implicatures and free choice effects

\subsection{Additional difficulties for the globalist approach: free choice}

However, the globalist approach also faces important new difficulties. These difficulties are restricted to free choice effects where it seems that universal inferences are robust even though they are not predicted.

At this point, there are two possible ways to go. First, one may simply deny that free choice inferences should be accounted for along with scalar implicatures. Second, one may argue that the universal guise of free choice inferences comes from an independent mechanism which does not extend to more standard cases of scalar implicatures. This last option might not require fundamental changes in our current understanding of these phenomena. Free choice inferences are derived thanks to a very subtle interaction between the precise definition of $\mathbf{O}$ and a set of alternatives with a particularly complex structure (compared to standard cases of implicatures). It could be that the landscape of alternatives is not quite right or that minor changes in the definition of $\mathbf{O}$ would not affect the result for simpler sets of alternatives (i.e. for standard scalar implicatures) but would derive these new universal inferences.

\subsection{Conclusions}

The present results call for a uniform treatment of positive and negative configurations (both for scalar and free choice effects) and this cannot be offered by localist means. However, the present results also call for a mechanism to derive specifically universal free choice inferences. In other words, the globalist approach is incomplete but the distribution of the additional universal inferences also escape to localist treatments.

In fact, similar puzzles involving surprising universal inferences come out in a wide variety of domains: scalar implicatures, free choice inferences, negraising, ${ }^{18}$ so-called homogeneity presuppositions of noun phrases, ${ }^{19}$ focus

18 See Horn (1978) and Gajewski (2005, 2007).

19 This is an immediate extension of Löbner's (2000) discussion of definite NPs for instance. The facts in (i) are well-known, they show that definite NPs give rise to an inference, sometimes described as a homogeneity presupposition, which resists negation.

(i) a. John read the books. $\rightsquigarrow$ John read all the books.

b. John didn't read the books. $\rightsquigarrow$ John didn't read any books.

The universal guise of this inference is revealed in (ii):

(ii) a. Every student read the books. $\rightsquigarrow$ Every student read all the books. 
and quasi-presuppositions, ${ }^{20}$ and presuppositions. ${ }^{21}$ Finally, these inferences might be independent from the universal force of the original quantifier to begin with (see (26) and (27) in appendix A.2). I leave a complete account of this whole phenomenon for future research, hopefully both formal and experimental.

\section{A Formal description of the operator $\mathrm{O}$}

In the main text, I did not explain the effects of the $\mathbf{O}$ operator in any detail. In this appendix, I repeat the relevant part of Fox's (2007) analysis of this operator. I would like to mention that the second subsection of this appendix, A.2, is of independent interest: new pieces of data are introduced and discussed in (i) to (iv).

\section{A.1 General definitions}

First, the role of $\mathbf{O}$ is always to negate a subset of the alternatives of a given sentence. I will refer to the set of alternatives of a sentence (or phrase) $S$ as $\operatorname{Alt}(S)$.

(21) $\operatorname{Alt}(S)=$ the set of alternatives of $S$

The role of $\mathbf{O}$ is to negate or exclude a subset of these alternatives. I will refer to this subset as $\operatorname{IE}(S)$ : the set of innocently excludable alternatives of $S$. We obtain the following two definitions/characterizations:

(22) $\operatorname{IE}(S)=$ the set of alternatives that are innocently excludable.

(23) $\mathrm{O}(S) \equiv \mathrm{S} \wedge(\bigwedge a \in \operatorname{IE}(S) \neg a)$

Finally, we need to define what it means to be innocently excludable. Intuitively, an alternative $a$ is innocently excludable if negating (excluding) this particular alternative does not impose new constraints on the truthvalues of other alternatives. More precisely, being innocently excludable places two requirements. First, the alternative must be excludable, i.e. its negation should be consistent with the sentence being true. Second, for every subset $A$ of globally excludable alternatives (meaning that all the alternatives

b. No student read the books. $\rightsquigarrow$ No student read any books.

20 See Abrusán (2009) and Chemla (2009a).

21 See debates between e.g., Heim (1983) and Beaver (1994) as discussed in Kadmon (2001, chapter 10). Relevant experimental data can be found in Chemla (2009b). 
Universal implicatures and free choice effects

in $A$ can be negated consistently with the sentence being true), $A \cup\{a\}$ must also be globally excludable, i.e. you can always negate $a$ as well as the other alternatives in $A$ and obtain a non-contradictory result.

(24) $\operatorname{IE}(S)=\bigcap\left\{A \subseteq \operatorname{Alt}(S): A\right.$ is a maximal set in $\operatorname{Alt}(S)$ s.t. $S \wedge\left(\bigwedge_{a \in A} \neg a\right)$ is not contradictory\}

\section{A.2 Multiple replacements and universal inferences}

It has been claimed that globalist approaches may predict universal inferences such as (25a), see van Rooij \& Schulz (2004), Spector (2006), Chemla (2009c). Indeed, the sentence (25b) can be seen as an alternative to the premise in (25a): it is obtained by replacing the scalar item 'some' with 'all' and also the scalar quantifier 'every' with 'some'.

(25) a. Every student read some of the books. $\rightsquigarrow$ No student read them all.

b. New alternative: Some student read all the books.

A globalist application of $\mathbf{O}$ would predict the inference that this new alternative is false (notice that this alternative is not weaker than the original sentence), which corresponds exactly to the universal inference in (25a).

I would like to mention four properties of this derivation.

(i) Quantifiers without universal force. This derivation applies equally well to other sentences without universal force in the first place. Provided that 〈some, most $\rangle$ and 〈 few, not all $\rangle$ are standard scales, this derivation predicts the following universal inferences which are not accessible to a localist derivation:

(26) Most students read some of the books.

$\rightsquigarrow$ No student read all the books.

(27) Few students read all the books.

$\rightsquigarrow$ All students read some of the books.

(ii) Epistemic status. This globalist derivation allows for the derivation of the implicature in its two usual versions:

(28) Every student read some of the books.

a. Primary implicature: the speaker doesn't (particularly) believe that any student read all the books. 
b. Secondary implicature: the speaker believes that no student read all the books.

(iii) No asymmetry. This derivation does not introduce an asymmetry between the positive and the negative configurations in the globalist approach because the very same derivation would be available in the negative configuration. The reader can check that the reasoning above applies equally to (29):

(29) a. No student read all the books. $\rightsquigarrow$ Every student read some books.

b. New alternative: Not all students read some of the books.

(iv) Not (clearly) available. There are arguments to say that alternatives like (25b) and (29b) should be blocked. In short, the idea is that there are cases where it is important to restrict $\operatorname{Alt}(S)$ to sentences which can be derived from $S$ in one-replacement steps of the form $S_{i} \rightarrow S_{i+1}$ such that $S_{i+1}$ is not weaker than $S_{i}$ (this being a much generalized version of the idea that weaker alternatives have no effect on implicature computation). These arguments are discussed in Fox (2007: fn 35) and Magri (2008: ex (65)). Notice however that these arguments may not apply to the theory developed in Chemla (2009c): in this system, multiple replacements like (25b) and (29b) do not lead to problematic predictions.

\section{A.3 Universal free choice inferences}

In a system based on an $\mathbf{O}$ operator à la Fox, free choice inferences are derived via rather involved computations and it would not be useful to go into detail about them here. Yet, I claimed without proof that a globalist application of $\mathbf{O}$ does not predict a universal free choice inference (end of section 1.6.3). I want to explain why this is so.

In non quantified cases, free choice effects arise via a double application of $\mathbf{O}$ (although this is not necessary, since simple modifications in the definition would remove this property, see footnote 10). In quantified cases, the universal inference is negated by the first application of $\mathbf{O}$ and thus could not be derived by later applications. The relevant steps are below but the short version of this is that every alternative gets negated in the first step and we derive for example that ' $\forall x: \diamond[A x]$ ' is false which blocks the universal inference.

a. $\mathrm{S}=\forall x: \diamond[A x \vee B x]$

(schematic logical form of (12b)) 
Universal implicatures and free choice effects

b. $\operatorname{Alt}(S)=\{\forall x: \diamond[A x], \forall x: \diamond[B x], \forall x: \diamond[A x \wedge B x]\}$

c. $\operatorname{IE}(S)=\operatorname{Alt}(S)$ (i.e. all the alternatives can be negated consistently)

d. $\mathbf{O}(S) \equiv \forall x: \diamond[A x \vee B x] \wedge \neg(\forall x: \diamond[A x]) \wedge \neg(\forall x: \diamond[B x])$

Notice that if we add the (problematic) alternatives discussed in A.2, where the universal quantifier $\forall$ is replaced with an existential quantifier $\exists$, we would still not derive the universal inference. The reason for this is that the set of innocently excludable alternatives is even bigger and their negations still block the universal inference. This is represented in the computations below where $S^{*}$ is exactly like $S$ above except that $S^{*}$ has more alternatives:

(31) Version 2 (including problematic alternatives, see A.2)

a. $S^{*}=\forall x: \diamond[A x \vee B x]$

b. $\operatorname{Alt}\left(S^{*}\right)=\{\forall x: \diamond[A x], \forall x: \diamond[B x], \forall x: \diamond[A x \wedge B x]$, $\exists x: \diamond[A x], \exists x: \diamond[B x], \exists x: \diamond[A x \wedge B x]\}$

c. $\operatorname{IE}\left(S^{*}\right)=\operatorname{IE}(S) \cup\{\exists x: \diamond[A x \wedge B x]\}$

d. $\mathbf{O}\left(S^{*}\right) \equiv \forall x: \diamond[A x \vee B x] \wedge \neg(\forall x: \diamond[A x]) \wedge \neg(\forall x: \diamond[B x]) \wedge$ $\neg(\exists x: \diamond[A x \wedge B x])$

\section{B Experimental instructions}

\section{B.1 Actual French version}

Bonjour et merci pour votre participation.

Vous allez voir s'afficher à l'écran des exemples de ce type:

$$
\left\langle\begin{array}{l}
\text { see figure } 2 \text { for the layout and example (32) in } \\
\text { appendix C for the French version of the items }
\end{array}\right\rangle
$$

Pour chaque phrase entre guillemets, vous direz si elle suggère "fortement" (à droite) ou "faiblement" (à gauche) ce qui suit (précédé du symbole “ $\rightarrow \rightarrow \rightarrow$ ”). Vous pourrez donner des réponses aussi variées que nécessaire pour coller à votre intuition en jouant sur la longueur de la ligne rouge.

Si les exemples (i) et (ii) ci-dessus n'appellent pas de commentaires, l'exemple (iii) est plus controversé. En entendant (iii) certains comprendraient que Jean est un excellent élève et que le prof veut qu'il fasse la correction pour ses camarades. D'autres comprendraient au contraire que le prof menace Jean de le démasquer. En suivant votre intuition propre, vous guiderez la ligne rouge plus ou moins proche de "Fort" ou de "Faible". Ce n'est pas un test de logique et il n'y a pas de bonne ou de mauvaise réponse. Tous les 
exemples se passent dans une salle de classe. Prêtez attention aux quelques informations plus spécifiques (appelées "Contexte général”) qui vous seront données sur les circonstances particulières pour chaque série de phrases (c'est-à-dire en haut de chaque cadre). Attention, ces informations ne sont valables que pour les exemples juste en dessous dans le même cadre.

Les phrases sont toutes indépendantes les unes des autres (comme si c'était chaque fois un autre prof avec d'autres étudiants, éventuellement dans le même "contexte général"). Oubliez-les au fur et à mesure. Jugez les phrases dans l'ordre où elles apparaissent à l'écran. Vous pouvez revenir sur vos jugements par exemple pour mettre en évidence des différences entre les phrases mais inutile de le faire systématiquement.

Jouez avec la longueur de la ligne pour indiquer clairement même de petites différences de force d'un exemple à un autre. Ne répondez pas "maximalement Fort" systématiquement sans chercher les différences!

Validez vos réponses en cliquant sur le bouton "Submit".

Gardez votre main sur la souris pour adapter la longueur des barres rouges aussitôt que vous vous serez fait un avis.

Les premiers exemples devraient vous aider mais si quelque chose ne vous semble pas clair, appelez l'expérimentateur maintenant.

\section{B.2 English translation}

Hello and thank you for your participation.

You are going to see examples on the screen of the following types:

〈see figure 2〉

For each sentence between quotation marks, you will say if it suggests "strongly" (to the right) or "weakly" (to the left) what follows (preceded with the symbol " $\rightarrow \rightarrow \rightarrow$ "). You can give answers as diverse as necessary to represent your intuition by playing with the length of the red line.

If examples (i) and (ii) above are clear, example (iii) is more controversial. Upon hearing (iii) some would understand that John is an excellent student and that the teacher wants him to do the correction for his fellow students. However, others may understand that the teacher is threatening John and that he has a way to prove that he cheated. Following your intuition, you will guide the red line more or less closely to "Strong" or "Weak". It is not a logic test and there is no good or bad answer. Every example has to be understood as if uttered in a classroom. Pay attention to the more specific information 
Universal implicatures and free choice effects

(called "General context") which will be given for each series of examples (on top of each frame). Caution: this information is active only for examples right below in the same frame.

The sentences are independent from each other (as if it was each time a new teacher with fresh students, potentially in the same "general context" though). Forget the examples as you go. Judge the sentences in the order they appear on the screen. You may occasionally return to your judgments to indicate more subtle differences between the sentences for instance, but there is no need to do it systematically.

Play with the length of the line to indicate clearly even small differences in strength from one example to the next. Do not answer "maximally strong" systematically without considering possible differences! Validate your answers with the button "Submit". Keep your hand on the mouse to adjust the length of the red lines as soon as you made up your mind. The first examples should help you but if anything is not clear, call the experimenter now.

\section{Experimental items}

In addition to the 3 training items repeated at the beginning of the experiment, the experiments contained 16 inferences. Each screen included 4 inferences which were variants of either 4 scalar implicatures or 4 free choice inferences discussed in section 1.6. The full list of experimental items is below, the English translations come right after each of the actual French examples.

\section{Training item}

(32) Contexte général: Le prof s'apprête à rendre les copies du dernier examen. Il annonce:

a. "Tout le monde a eu une excellente note." $\rightarrow$ Tout le monde a réussi son examen.

b. "Jean a eu une très mauvaise note." $\rightarrow$ Jean a réussi son examen.

c. "J'aimerais voir Jean faire la correction au tableau." $\rightarrow$ Jean a triché.

(32') Translation of (32) (repeated from Fig. 2):

General context: The teacher is about to give the results of the last exams. He says:

a. "Everyone had an excellent grade." $\rightarrow$ Everyone passed his exam.

b. "John had a very bad grade." $\rightarrow$ John passed his exam. 
c. "I'd like to see John going through everything again for us on the blackboard." $\rightarrow$ Jean cheated.

\section{Scalar implicature items}

(a): positive cases, (b): negative cases. (i): "Individual" inferences; (ii): "Universal" inferences.

(33) a. Contexte général: Les étudiants viennent de passer une dizaine d'examens. Le professeur annonce quelques résultats:

i. "Paul a réussi la plupart de ses examens." $\rightarrow$ Paul ne les a pas tous réussis.

ii. "Tout le monde a réussi la plupart de ses examens." $\rightarrow$ Personne ne les a tous réussis.

b. Contexte général: Les étudiants viennent de passer une dizaine d'examens. Le professeur donne les résultats:

i. "Paul n’a pas réussi tous ses examens." $\rightarrow$ Paul en a réussi une partie.

ii. "Personne n'a réussi tous ses examens." $\rightarrow$ Tout le monde en a réussi une partie.

(33') Translation of (33)

a. General context: The students just had a series of 10 exams. The teacher gives some results:

i. "Paul passed most of his exams." $\rightarrow$ Paul didn't pass them all.

ii. "Everyone passed most of his exams." $\rightarrow$ No one passed them all.

b. General context: The students just had a series of 10 exams. The teacher give some results:

i. "Paul didn't pass all his exams." $\rightarrow$ Paul passed some of them.

ii. "No one passed all his exams." $\rightarrow$ Everyone passed some of them.

(34) a. Contexte général: Les étudiants avaient vingt dates d'événements historiques à apprendre et il y a eu un contrôle surprise. Le professeur a corrigé les copies et il annonce:

i. "Paul s'est souvenu de la plupart des dates." $\rightarrow$ Paul ne s'est pas souvenu de toutes les dates. 
Universal implicatures and free choice effects

ii. "Tout le monde s'est souvenu de la plupart des dates." $\rightarrow$ Personne ne s'est souvenu de toutes les dates.

b. Contexte général: Les étudiants avaient vingt dates d'événements historiques à apprendre et il y a eu un contrôle surprise. Le professeur a corrigé les copies et il annonce:

i. "Paul ne s'est pas souvenu de toutes les dates." $\rightarrow$ Paul s'en est souvenu d'une partie.

ii. "Personne ne s'est souvenu de toutes les dates." $\rightarrow$ Tout le monde s'en est souvenu d'une partie.

\section{(34') Translation of (34)}

a. General context: The students had 20 historical dates to remember and there was a surprise exam. The teacher corrected the copies and now says:

i. "Paul remembered most of the dates." $\rightarrow$ Paul didn't remember all the dates.

ii. "Everyone remembered most of the dates." $\rightarrow$ No one remembered all the dates.

b. General context: The students had 20 historical dates to remember and there was a surprise exam. The teacher corrected the copies and now says:

i. "Paul didn't remember all the dates." $\rightarrow$ Paul remembered some of them.

ii. "No one remembered all the dates." $\rightarrow$ Everyone remembered some of them.

\section{Free choice items}

For each of the following examples, the items given in (a) correspond to positive cases while the items described in (b) are the corresponding negative cases. The examples in (i) are the "Individual" inferences and the examples in (ii) are their corresponding "Universal" inferences.

(35) a. Contexte général: On sait que personne n'aura le droit de rendre à la fois la dissertation et le commentaire. Le prof donne des instructions supplémentaires:

i. "Jean a le droit de rendre la dissertation ou le commentaire." $\rightarrow$ Jean peut choisir lequel des deux il rendra. 
ii. "Tout le monde a le droit de rendre la dissertation ou le commentaire." $\rightarrow$ Chacun peut choisir lequel des deux il rendra.

b. Contexte général: On sait que tout le monde va devoir rendre (au moins) la dissertation ou le commentaire (on ne sait pas encore si certains devront rendre les deux). Le prof donne des instructions supplémentaires:

i. "Jean n'est pas obligé de rendre la dissertation et le commentaire." $\rightarrow$ Jean peut choisir lequel des deux il rendra.

ii. "Personne n'est obligé de rendre la dissertation et le commentaire." $\rightarrow$ Chacun peut choisir lequel des deux il rendra.

(35') Translation of (35) in Fig. 3

(36) a. Contexte général: On sait que personne n'aura le droit de s'inscrire en algèbre et en littérature. Le prof donne des instructions supplémentaires:

i. "Marie a le droit de s'inscrire en algèbre ou en littérature." $\rightarrow$ Marie peut choisir auquel des deux elle s'inscrira.

ii. "Tout le monde a le droit de s'inscrire en algèbre ou en littérature." $\rightarrow$ Chacun peut choisir auquel des deux il s'inscrira.

b. Contexte général: On sait que tout le monde va devoir s'inscrire (au moins) en algèbre ou en littérature (on ne sait pas encore si certains devront s'inscrire aux deux). Le prof donne des instructions supplémentaires:

i. "Marie n'est pas obligée de s'inscrire en algèbre et en littérature." $\rightarrow$ Marie peut choisir auquel des deux elle s'inscrira.

ii. "Personne n'est obligé de s'inscrire en algèbre et en littérature." $\rightarrow$ Chacun peut choisir auquel des deux il s'inscrira.

\section{$\left(36^{\prime}\right)$ Translation of (36)}

a. General context: We know that no one will be allowed to take Algebra and Literature. The teachers give further instructions:

i. "Marie is allowed to take Algebra or Literature." $\rightarrow$ Marie can choose which she will take.

ii. "Everyone is allowed to take Algebra or Literature." $\rightarrow$ Everyone can choose which he will take.

b. General context: We know that everyone will be required to take (at least) Algebra or Literature (we don't know yet whether some will have to take both). The teachers give further instructions: 
Universal implicatures and free choice effects

i. "Marie is not required to take Algebra and Literature." $\rightarrow$ Marie can choose which she will take.

ii. "No one is required to take Algebra and Literature." $\rightarrow$ Everyone can choose which he will take.

\section{References}

Abrusán, Márta. 2009. Notes about quasi-presuppositions. Ms, Institute Jean Nicod.

Alonso-Ovalle, Luis. 2005. Distributing the disjuncts over the modal space. Proceedings of the North East Linguistics Society 35. URL http://www. alonso-ovalle.net/papers/alonso-ovalle_NELS2005.pdf.

Bach, Kent. 2002. Semantic, pragmatic. In Campbell, Joseph Keim, Michael O'Rourke \& David Shier (eds.), Meaning and truth: Investigations in philosophical semantics (Topics in Contemporary Philosophy 1), 284-292. New York: Seven Bridges Press.

Bard, Ellen Gurman, Dan Robertson \& Antonella Sorace. 1996. Magnitude estimation of linguistic acceptability. Language 72(1). 32-68. doi:10.2307/416793.

Beaver, David I. 1994. When variables don't vary enough. Proceedings of Semantics and Linguistic Theory 4. 35-6o.

Bech, Gunnar. 1955. Studien über das Deutsche Verbum Infinitum (Linguistische Arbeiten 139). Tübingen: Niemeyer.

Carston, Robyn. 2002. Thoughts and Utterances: The Pragmatics of Explicit Communication. Oxford: Blackwell. doi:10.1002/9780470754603.

Chemla, Emmanuel. 20oga. An experimental approach to adverbial modification. In Uli Sauerland \& Kazuko Yatsushiro (eds.), Semantics and pragmatics: From experiment to theory. In press.

Chemla, Emmanuel. 20ogb. Presuppositions of quantified sentences: experimental data. Natural Language Semantics doi:10.1007/s11050-009-9043-9. In press.

Chemla, Emmanuel. 2009c. Similarity: Towards a unified account of scalar implicatures, free choice permission and presupposition projection. Under revision for Semantics and Pragmatics.

Chierchia, Gennaro. 2004. Scalar implicatures, polarity phenomena, and the syntax/pragmatics interface. In Adriana Belletti (ed.), Structures and beyond: The cartography of syntactic structures, vol. 3, 39-103. Oxford University Press. 
Chierchia, Gennaro, Danny Fox \& Benjamin Spector. 2008. The grammatical view of scalar implicatures and the relationship between semantics and pragmatics. In Claudia Maienborn, Klaus von Heusinger \& Paul Portner (eds.), Handbook of semantics. Mouton de Gruyter. URL http: //semanticsarchive.net/Archive/WMzY2ZmY/CFS_EmbeddedSIs.pdf. To appear.

Cohen, Jonathan L. 1971. Some remarks on Grice's views about the logical particles of natural language. In Bar Hillel, Yehoshua (ed.), Pragmatics of natural languages, 50-68. Dordrecht: Reidel.

Cowart, Wayne. 1997. Experimental syntax: Applying objective methods to sentence judgments. Thousand Oaks, CA: Sage Publications.

Ducrot, Oswald. 1969. Présupposés et sous-entendus. Langue Française 4(4). 30-43. doi:10.3406/lfr.1969.5456.

Fox, Danny. 2007. Free choice and the theory of scalar implicatures. In Uli Sauerland \& Penka Stateva (eds.), Presupposition and implicature in compositional semantics, 537-586. New York: Palgrave Macmillan.

Gajewski, Jon Robert. 2005. Neg-raising: Polarity and presupposition. Ph.D. thesis, Massachusetts Institute of Technology. doi:1721.1/33696.

Gajewski, Jon Robert. 2007. Neg-raising and polarity. Linguistics and Philosophy 30(3). 289-328. doi:10.1007/s10988-007-9020-z.

Gazdar, Gerald. 1979. Pragmatics: Implicature, presupposition and logical form. New York: Academic Press.

Geurts, Bart. 1996. On No. Journal of Semantics 13(1). 67-86. doi:10.1093/jos/13.1.67.

Geurts, Bart \& Nausicaa Pouscoulous. 2008. No scalar inferences under embedding. In Paul Egré \& Giorgio Magri (eds.), Presuppositions and implicatures. MIT Working Papers in Linguistics.

Grice, Paul. 1967. Logic and conversation. Lecture notes for William James lectures at Harvard University, published in slightly revised form in Grice (1989: 1-143).

Grice, Paul. 1989. Studies in the way of words. Cambridge, MA: Harvard University Press.

Groenendijk, Jeroen \& Martin Stokhof. 1997. Questions. In Johan van Benthem \& Alice ter Meulen (eds.), Handbook of logic and language, 1055-1124. Elsevier. doi:10.1016/B978-044481714-3/50024-2.

Heim, Irene. 1983. On the projection problem for presuppositions. Proceedings of WCCFL 2. 114-125.

Horn, Laurence R. 1972. On the semantic properties of logical operators in 
Universal implicatures and free choice effects

English. Ph.D. thesis, UCLA.

Horn, Laurence R. 1978. Remarks on neg-raising. In Peter Cole (ed.), Pragmatics (Syntax and Semantics 9), 129-220. New York: Academic Press.

Jacobs, Joachim. 1980. Lexical decomposition in Montague-grammar. Theoretical Linguistics 7(1-2). 121-136.

Kadmon, Nirit. 2001. Formal pragmatics: Semantics, pragmatics, presupposition, and focus. Blackwell.

Kamp, Hans. 1973. Free choice permission. Proceedings of the Aristotelian Society, New Series 74. 57-74.

Katzir, Roni. 2007. Structurally-defined alternatives. Linguistics and Philosophy 30(6). 669-690. doi:10.1007/s10988-008-9029-y.

Kratzer, Angelika. 1995. Individual-level and stage-level predicates. In Greg N. Carlson \& Francis Jeffry Pelletier (eds.), The generic book, 125-175. University of Chicago Press.

Kratzer, Angelika \& Junko Shimoyama. 2002. Indeterminate pronouns: The view from Japanese. In Yukio Otsu (ed.), The proceedings of the Third Tokyo Conference on Psycholinguistics, 1-25. Tokyo: Hituzi Syobo. URL http://semanticsarchive.net/Archive/WEwNjc4Z/ Indeterminate\%2oPronouns.pdf.

Landman, Fred. 1998. Plurals and maximalization. In Susan Rothstein (ed.), Events and grammar, 237-271. Kluwer.

Levinson, Stephen C. 200o. Presumptive meanings: The theory of generalized implicature. MIT Press.

Löbner, Sebastian. 200o. Polarity in natural language: Predication, quantification and negation in particular and characterizing sentences. Linguistics and Philosophy 23(3). 213-308. doi:10.1023/A:1005571202592.

Magri, Giorgio. 2008. A theory of individual level predicates based on blind scalar implicatures. URL http://web.mit.edu/gmagri/www/papers/ ILP(ExtendedVersion).pdf. Ms, MIT.

Matsumoto, Yo. 1995. The conversational condition on Horn scales. Linguistics and Philosophy 18(1). 21-6o. doi:10.1007/BFoog84960.

Penka, Doris \& Arnim von Stechow. 2001. Negative Indefinita unter Modalverben. In Reimar Müller \& Marga Reis (eds.), Modalität und Modalverben im Deutschen, 263-286. Hamburg: Buske Verlag.

Potts, Christopher. 2000. When even no's neg is splitsville. In Sandy Chung, Jim McCloskey \& Nathan Sanders (eds.), Jorge Hankamer webfest. URL http://ling.ucsc.edu/Jorge/potts.html.

Recanati, François. 2003. Embedded implicatures. Philosophical Perspectives 
Emmanuel Chemla

17(1). 299-332. doi:10.1111/j.1520-8583.2003.00012.x.

Recanati, François. 2004. Literal meaning. Cambridge University Press. doi:10.2277/0521537363.

van Rooij, Robert \& Katrin Schulz. 2004. Exhaustive interpretation of complex sentences. Journal of Logic, Language and Information 13(4). 491-519. doi:10.1007/s10849-004-2118-6.

Sauerland, Uli. 2004. Scalar implicatures in complex sentences. Linguistics and Philosophy 27(3). 367-391. doi:10.1023/B:LING.0oooo23378.71748.db.

Schulz, Katrin. 2003. You may read it now or later: A case study on the paradox of free choice permission. Master's thesis, University of Amsterdam.

Schütze, Carson T. 1996. The empirical base of linguistics: Grammaticality judgments and linguistic methodology. University of Chicago Press.

Sharvit, Yael \& Jon R. Gajewski. 2008. On the calculation of local implicatures. Proceedings of WCCFL 26. 411-419.

Spector, Benjamin. 2003. Scalar implicatures: Exhaustivity and Gricean reasoning. In Balder ten Cate (ed.), Proceedings of the Eighth ESSLLI Student Session. Vienna, Austria. Revised version in Spector (2007b).

Spector, Benjamin. 2006. Aspects de la pragmatique des opérateurs logiques. Ph.D. thesis, Université Paris 7.

Spector, Benjamin. 2007a. Aspects of the pragmatics of plural morphology: On higher-order implicatures. In Uli Sauerland \& Penka Stateva (eds.), Presuppositions and implicatures in compositional semantics, 243-281. New York: Palgrave Macmillan.

Spector, Benjamin. 2007b. Scalar implicatures: Exhaustivity and Gricean reasoning. In Maria Aloni, Paul Dekker \& Alastair Butler (eds.), Questions in dynamic semantics (Current Research in the Semantics/Pragmatics Interface 17), 225-249. Elsevier.

Stevens, Stanley Smith. 1956. The direct estimation of sensory magnitudes-loudness. American Journal of Psychology 69(1). 1-25. doi:10.2307/1418112.

Szabó, Zoltán Gendler (ed.). 2006. Semantics versus pragmatics. Oxford University Press. 
Universal implicatures and free choice effects

Emmanuel Chemla

Ecole Normale Supérieure - LSCP

29 rue d'Ulm

75005 Paris

France

chemla@ens.fr 